Article

\title{
The Influence of Anode Trench Geometries on Electrical Properties of AlGaN/GaN Schottky Barrier Diodes
}

\author{
Xiuxia Yang ${ }^{1,2}$, Zhe Cheng ${ }^{1}$, Zhiguo Yu ${ }^{1}$, Lifang Jia ${ }^{1}$, Lian Zhang ${ }^{1}$ and Yun Zhang ${ }^{1,2, *}$ \\ 1 Laboratory of Solid State Optoelectronics Information Technology, Institute of Semiconductors, Chinese \\ Academy of Sciences, Beijing 100083, China; yangxiuxia@semi.ac.cn (X.Y.); zhecheng@semi.ac.cn (Z.C.); \\ zgyu@semi.ac.cn (Z.Y.); Lfjia@semi.ac.cn (L.J.); zhanglian07@semi.ac.cn (L.Z.) \\ 2 Center of Materials Science and Optoelectronics Engineering, University of Chinese Academy of Sciences, \\ Beijing 100049, China \\ * Correspondence: yzhang34@semi.ac.cn
}

Received: 8 January 2020; Accepted: 4 February 2020; Published: 7 February 2020

\begin{abstract}
AlGaN/GaN lateral Schottky barrier diodes (SBDs) with three different anode geometries (stripe, circular, and the conventional plane one) and different rows of anode trenches are fabricated and electrically characterized to study the influence of anode trench geometries. The SBDs with anode trenches exhibit the lower on-state resistance $\left(\mathrm{R}_{\mathrm{ON}}\right)$ than that with the conventional plane one. It can be explained that the anode trenches made the Schottky metal directly contact to the 2DEG at the sidewall of the $\mathrm{AlGaN} / \mathrm{GaN}$ interface, removing the $\mathrm{AlGaN}$ barrier layer in the conventional plane anode. In addition, the $\mathrm{R}_{\mathrm{ON}}$ of the SBDs with circular trenches is smaller than that of the SBDs with stripe ones. Furthermore, the $\mathrm{R}_{\mathrm{ON}}$ decreases with the increasing rows of anode trenches, which can be attributed to the increased contact area between the Schottky metal and the 2DEG. For the reverse characteristics, the anode trenches do not lead to performance degradation. The fabricated devices exhibit the low reverse current $\left(I_{R}, I_{R}<1 \mu \mathrm{A} / \mathrm{mm}\right)$, and the breakdown voltage $\left(V_{B K}\right)$ remains unchanged with different anode geometries.
\end{abstract}

Keywords: GaN; Schottky barrier diode; breakdown voltage; anode trenches

\section{Introduction}

$\mathrm{GaN}$ is one of the most suitable material candidates for power electronics and has attracted tremendous research interests due to the unique material properties. Recently, the $\mathrm{AlGaN} / \mathrm{GaN}$ heterostructures have been the subject of intense research for application in high-voltage/high-power electronic devices and optoelectronic devices [1,2]. GaN power devices can operate at high temperature, high voltage, and high speed thanks to the large bandgap, superior breakdown field strength, and excellent electron saturation velocity. Among $\mathrm{GaN}$ power devices, $\mathrm{GaN}$ diode rectifiers are indispensable devices in power switching applications, such as switch mode power supplies, converters, and inverters. AlGaN/GaN Schottky barrier diodes (SBDs), as one of the most popular members of the GaN rectifier family, are attracting great attention since they can be easily and monolithically integrated with GaN transistors [3]. However, conventional AlGaN/GaN SBDs suffer from large on-state resistance $\left(\mathrm{R}_{\mathrm{ON}}\right)$ because the AlGaN barrier hinders the forward current. Approaches such as anode trench SBDs [4] and anode with dual metals $[5,6]$ have been proposed to address the challenge. Among these methods, the anode trench technology is widely used in SBDs and reported in a number of literature. For example, anode trenches combined with carbon-doped GaN [7], AlGaN back-barrier [8], and field-plate structure $[9,10]$ have been used to reduce the $R_{\mathrm{ON}}$ and improve the breakdown voltage $\left(\mathrm{V}_{\mathrm{BK}}\right)$. 3D anode trenches combined with insulated tri-gate metal-oxide-semiconductor (MOS) 
structure [11] or gated edge termination structure [12] have been reported to reduce the $\mathrm{R}_{\mathrm{ON}}$ and realize an ultra-low reverse current $\left(I_{R}\right)$. In addition, nano-patterned anode trenches have been fabricated in $\mathrm{AlGaN} / \mathrm{GaN}$ SBDs with a series of periodically spaced trenches [8] to reduce $\mathrm{R}_{\mathrm{ON}}$ and $\mathrm{I}_{\mathrm{R}}$. Moreover, nanowire hybrid tri-anode and tri-gate structures present high $\mathrm{V}_{\mathrm{BK}}$ and low $\mathrm{R}_{\mathrm{ON}}$ [10-12]. However, there is little literature reporting the influence of anode trench geometry on the electrical properties of SBDs. In order to further improve the device performance in power applications, clarifying the effect of the anode geometries on the SBDs is one of the fundamental issues for anode trench SBDs.

In this letter, $\mathrm{AlGaN} / \mathrm{GaN}$ SBDs with three different anode geometries (stripe, circular, and the conventional plane one) and different rows of anode trenches are fabricated and electrically characterized to study the influence of anode trench geometries. $\mathrm{R}_{\mathrm{ON}}$ is sensitive to the anode shapes. The SBDs with circular anode trenches possess lower $\mathrm{R}_{\mathrm{ON}}$ than that with stripe anode trenches at the same number of rows. In addition, the more rows of anode trenches, the smaller the $\mathrm{R}_{\mathrm{ON}}$, which can be interpreted that the longer the perimeter, the larger the proportion of the Schottky metal directly in contact with the two dimensional electron gas (2DEG) at the sidewall of the AlGaN/GaN interface. In addition, the anode trenches reduce the $\mathrm{R}_{\mathrm{ON}}$ without sacrificing the reverse characteristics compared with the conventional plane one. In addition, the fabricated devices exhibit a low $\mathrm{I}_{R}(<1 \mu \mathrm{A} / \mathrm{mm})$. Moreover, the $\mathrm{V}_{\mathrm{BK}}$ is not degraded by the anode trenches.

\section{Experiment}

The epitaxial layers were grown by metal organic chemical vapor deposition (MOCVD) on a two-inch sapphire substrate [13], consisting of $2 \mu \mathrm{m}$ high resistance GaN (HR-GaN), $100 \mathrm{~nm}$ undoped $\mathrm{GaN}$ (u-GaN) channel, $1 \mathrm{~nm}$ AlN, $25 \mathrm{~nm}$ undoped $\mathrm{Al}_{0.26} \mathrm{Ga}_{0.74} \mathrm{~N}\left(\mathrm{u}-\mathrm{Al}_{0.26} \mathrm{Ga}_{0.74} \mathrm{~N}\right)$ barrier, and a $2 \mathrm{~nm}$ $\mathrm{u}-\mathrm{GaN}$ cap layer. For comparison, three types of anode geometries were designed, which were the conventional plane, stripe, and the circular one. A cross sectional schematic of the fabricated anode trench SBD is shown in Figure 1a, and the top view of different anode geometries is shown in Figure 1b. The length and width of the stripe trench were fixed at $100 \mu \mathrm{m}$ and $10 \mu \mathrm{m}$, respectively. The spacing between the two adjacent stripe trenches was $5 \mu \mathrm{m}$. The diameter of circular trenches was $10 \mu \mathrm{m}$, with the other parameters the same as the stripe ones. In addition, the number of rows were changed from one to four for SBDs with anode trenches. The anode area of all samples was $120 \mu \mathrm{m} \times 120 \mu \mathrm{m}$. The distance between anode and cathode $\left(\mathrm{L}_{\mathrm{AC}}\right)$ was set as $10 \mu \mathrm{m}, 15 \mu \mathrm{m}$, and $20 \mu \mathrm{m}$, respectively.

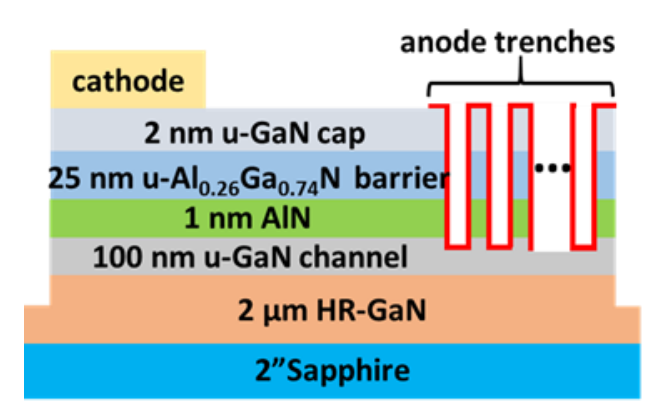

(a)

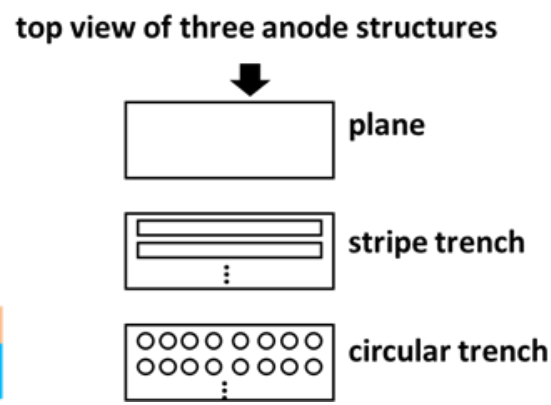

(b)

Figure 1. (a) schematic view of fabricated Schottky barrier diodes (SBD) with one type of the anode trenches; (b) the top view of three anode geometries, and the number of rows is changed from 1 to 4 .

Device fabrication started with mesa isolation by using inductively coupled plasma (ICP) etching [14], and the depth was about $400 \mathrm{~nm}$. Subsequently, the stripe arrays and circular arrays were patterned onto the samples. Then, the anode trenches were also accomplished by ICP etching down to the $\mathrm{GaN}$ channel layer with an etch depth of about $50 \mathrm{~nm}$. Afterwards, the cathode metal consisting of Ti/Al/Ti/Au [15] (20/100/50/70 nm) was deposited by electron-beam evaporation and annealed at $870{ }^{\circ} \mathrm{C}$ for $30 \mathrm{~s}$ in nitrogen ambient [16]. After the formation of ohmic contact, a Ni/Au [17] (100/50 nm) 
metal stack was used for Schottky contact. Moreover, all devices were fabricated on the same wafer for fair comparison.

\section{Results}

The anode trench depth was about $50 \mathrm{~nm}$ measured by the Dektak Profilometer (Veeco Instruments Inc, Plainview, NY, USA). In Figure 2, the root-mean-square (RMS) surface roughness before and after etching was $0.357 \mathrm{~nm}$ and $0.362 \mathrm{~nm}$, respectively, measured by a dimension 3100 atomic force microscope system (Veeco Instruments Inc, Plainview, NY, USA). Hence, the dry etching had little impact on the surface roughness. In addition, the cathode contact resistivity $\rho_{\mathrm{c}}$ of $4.45 \times 10^{-5} \Omega \bullet \mathrm{cm}^{2}$ and sheet resistance $R_{\text {sh }}$ of $359 \Omega / \square$ were calculated by the transmission line method (TLM) based on measurement by a Keithley 4200 Semiconductor Characterization System (Tektronix Inc, Beaverton, USA).

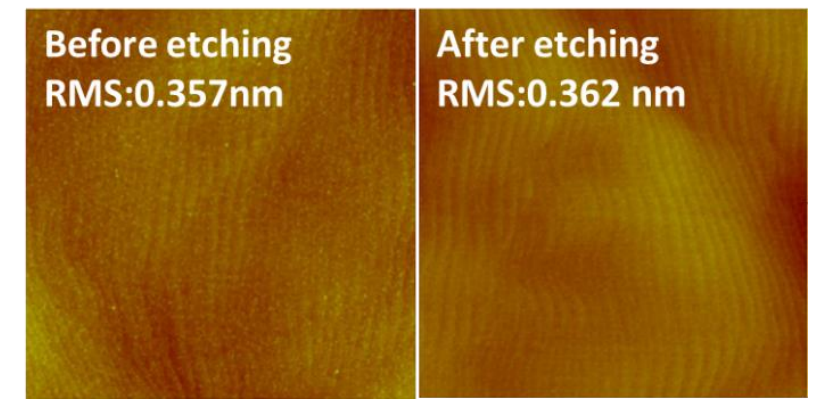

Figure 2. Atomic force microscopy (AFM) images of the surface before etching and after etching of $5 \times 5 \mu \mathrm{m}^{2}$.

Typical forward rectifying characteristics of SBDs with three different anode geometries (the conventional plane, stripe, and circular one) are compared in Figure 3a, with the number of trenches rows kept at 4 and $L_{A C}=10 \mu \mathrm{m}$. The forward I-V curves can be divided into three parts. When the forward voltage $\left(\mathrm{V}_{\mathrm{F}}\right)$ ranges between $0 \mathrm{~V}$ and $0.3 \mathrm{~V}$, the current is dominated by a recombination current. The recombination current may be related to carrier recombination at the $\mathrm{GaN} / \mathrm{metal}$ interface. In this part, the SBDs with anode trenches have larger current than that of a conventional plane due to the larger surface recombination rate [18,19], as shown in the inset of Figure 3a. In the range between $0.3 \mathrm{~V}$ and $1.7 \mathrm{~V}$, where the diffusion current dominates, the currents of SBDs with three anode geometries are almost the same, indicating that the devices with different anode geometries have the similar $\mathrm{V}_{\mathrm{ON}}$ and Schottky barrier height (SBH). In the range between $1.7 \mathrm{~V}$ and $3 \mathrm{~V}$, the current is determined by the series resistance. In this voltage range, the SBDs with anode trenches have a larger current than that of the conventional plane due to the reduced series resistance. For the SBDs with other trenches' rows, the I-V characteristics are similar.

Especially, we extracted the $\mathrm{V}_{\mathrm{ON}}$ and $\mathrm{R}_{\mathrm{ON}}$ of SBDs with different anode shapes and rows of anode trenches from the measured I-V curves, as shown in Figure $3 b$,c. The $\mathrm{V}_{\mathrm{ON}}$ is obtained at the forward current $\left(I_{F}\right)$ of $1 \mathrm{~mA} / \mathrm{mm}[9,20]$, and the $R_{O N}$ is the inverse of the slope of the I-V curves in the linear region, as shown in Figure 3a. The devices with different anode geometries have the similar $\mathrm{V}_{\mathrm{ON}}$ between $0.8 \mathrm{~V}$ and $0.9 \mathrm{~V}$. We guess the possible reason is that dry etching causes an increase in the metal/2DEG contact barrier, leading to the similar contact barrier of metal/2DEG and metal/AlGaN [21,22]. In contrast to $\mathrm{V}_{\mathrm{ON}}, \mathrm{R}_{\mathrm{ON}}$ is sensitive to the shapes of anode trenches. The SBDs with anode trenches have the lower $\mathrm{R}_{\mathrm{ON}}$ compared with conventional plane ones because the anode trenches make the Schottky metal in direct contact with the 2DEG [4,6], removing the AlGaN barrier layer in the conventional plane. The $\mathrm{R}_{\mathrm{ON}}$ of the SBDs with circular trenches is smaller than that of the SBDs with stripe ones because the circular trenches have the larger perimeter, causing the larger contact area at the metal/2DEG interface and the more current flows through the Schottky interface. In addition, as the rows of anode trenches increased, the $\mathrm{R}_{\mathrm{ON}}$ decreased, which is due to the further 
increase of the contact area. Figure $3 \mathrm{~d}$ shows the relationship between the perimeter and $\mathrm{R}_{\mathrm{ON}}$. It shows that $\mathrm{R}_{\mathrm{ON}}$ decreases monotonically with the perimeter.
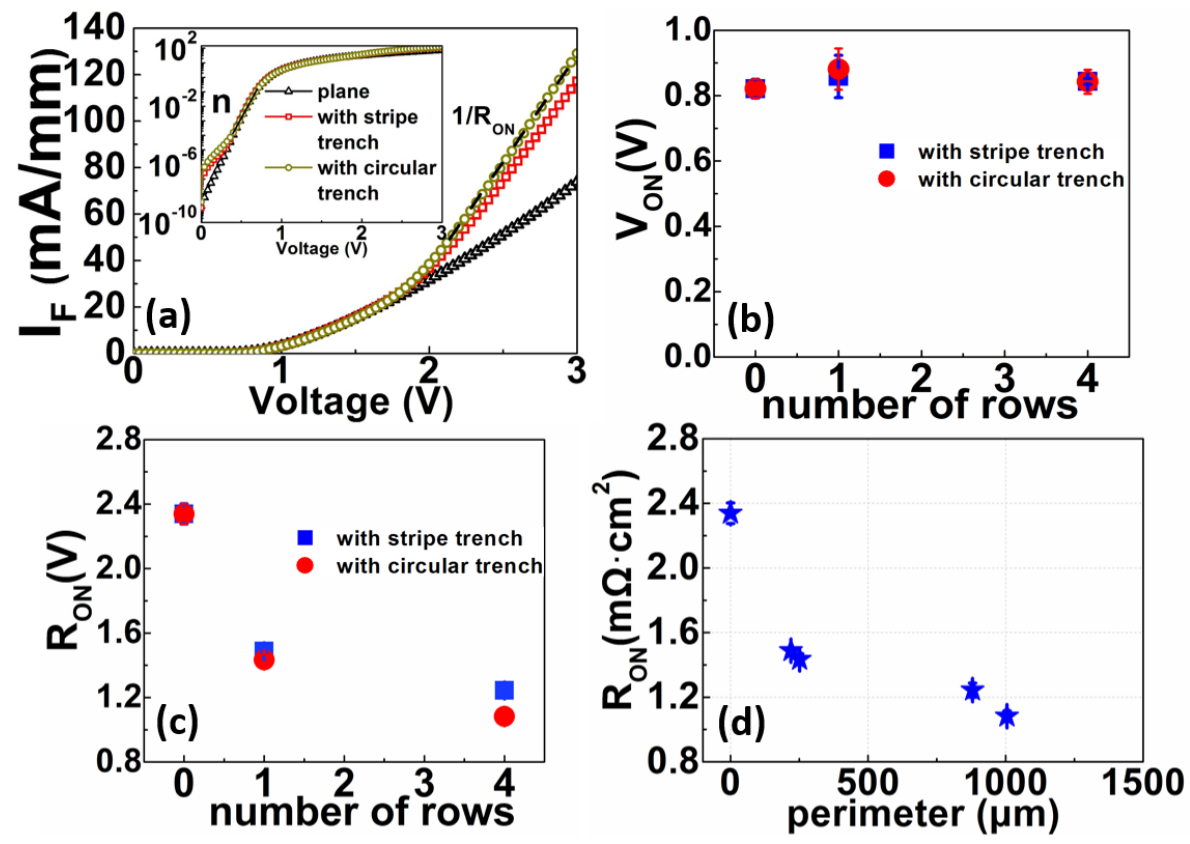

Figure 3. (a) the forward characteristics of the SBDs with three different anode geometries (with four rows of circular anode trenches and $\mathrm{L}_{\mathrm{AC}}=10 \mu \mathrm{m}$ ). Inset: log scale of the forward-bias regime. The dash line in (a) illustrates the definition of $R_{O N}$ used in this letter; (b) the $V_{O N}\left(I_{F}=1 \mathrm{~mA} / \mathrm{mm}\right)$ of SBDs with three different anode geometries vs. number of rows. (The conventional plane has 0 rows of anode trenches); (c) the $\mathrm{R}_{\mathrm{ON}}$ of SBDs with different anode geometries vs. number of rows; (d) the $\mathrm{R}_{\mathrm{ON}}$ of SBDs with different perimeters of anode trenches (The perimeter of the conventional plane is $0 \mu \mathrm{m}$ ).

Figure 4a shows the reverse characteristic curves of SBDs with three different anode geometries (the conventional plane, stripe, and circular one), with the row of trenches kept at 4 and $\mathrm{L}_{\mathrm{AC}}=10 \mu \mathrm{m}$. All of the devices have the extremely low reverse leakage current $\mathrm{I}_{\mathrm{R}}(<0.1 \mu \mathrm{A} / \mathrm{mm})$ at the initial $0 \sim-150 \mathrm{~V}$ and then slowly increase with the reverse voltage until breakdown at around $410 \mathrm{~V}$. Especially, $\mathrm{I}_{\mathrm{R}}$ and $\mathrm{V}_{\mathrm{BK}}$ with different rows are extracted from the I-V curves, as shown in Figure $4 b$,c. The $V_{\mathrm{BK}}$ is obtained at the reverse current of $1 \mathrm{~mA} / \mathrm{mm}$. In addition, the $I_{R}$ is the reverse current at the reverse voltage of $200 \mathrm{~V}$. The $\mathrm{I}_{\mathrm{R}}$ of the devices is between $6 \times 10^{-8}$ and $1 \times 10^{-7} \mathrm{~A} / \mathrm{mm}(<1 \mu \mathrm{A} / \mathrm{mm})$ for all devices, implying that $I_{R}$ is independent of shapes and rows of anode trenches. It indicates that no obvious lattice damage and deteriorated leakage current were introduced by the etching process. Therefore, the trench structures may not cause significant degradation of the reliability. The possible reason is that the forward current path is from the sidewall Schottky contact of the anode trench. However, a proper reverse bias makes the 2DEG completely depleted, and the currents tunneling through the sidewall Schottky contact are blocked. Consequently, the reverse current path mainly ran through the overlapped planar Schottky contact. Accordingly, the $I_{R}$ of SBDs with anode trenches is not sacrificed compared with conventional plane [23]. Figure $4 \mathrm{c}$ shows that the $\mathrm{V}_{\mathrm{BK}}$ of all the devices is between $400 \mathrm{~V}$ and $425 \mathrm{~V}$. There is no noticeable difference observed between the conventional plane and trench structures, meaning that $\mathrm{V}_{\mathrm{BK}}$ was not degraded by the anode trenches [6].

The typical forward bias characteristics of SBDs with different $\mathrm{L}_{\mathrm{AC}}$ are compared in Figure $5 \mathrm{a}$. The anode shape is selected as a circle, and the row of the anode trench is $4 . \mathrm{I}_{\mathrm{F}}\left(\mathrm{V}_{\mathrm{F}}=3 \mathrm{~V}\right)$ decreases with the increase of $\mathrm{L}_{\mathrm{AC}}$, indicating that $\mathrm{R}_{\mathrm{ON}}$ decreases with the increase of $\mathrm{L}_{\mathrm{AC}}$. The $\mathrm{V}_{\mathrm{ON}}$ and $\mathrm{R}_{\mathrm{ON}}$ of SBDs with different $\mathrm{L}_{\mathrm{AC}}$ and row numbers are extracted from I-V curves, as shown in Figure $5 b$,c. Figure $5 b$ depicts the $\mathrm{V}_{\mathrm{ON}}$ as being practically independent of $\mathrm{L}_{\mathrm{AC}}[9,24,25]$. Figure $5 \mathrm{c}$ shows the $\mathrm{R}_{\mathrm{ON}}$ naturally 
scales with $\mathrm{L}_{\mathrm{AC}}$, which is consistent with reported literature [20]. Consequently, the $\mathrm{R}_{\mathrm{ON}}$ is mainly related to the series resistance. The longer the $\mathrm{L}_{\mathrm{AC}}$, the larger the series resistance. Figure $5 \mathrm{~d}$ shows the $\mathrm{V}_{\mathrm{BK}}$ of the fabricated diodes with various $\mathrm{L}_{\mathrm{AC}}$. The higher the $\mathrm{L}_{\mathrm{AC}}$, the more pronounced is the reverse blocking capability of the SBDs $[5,13,14]$. This led to the well-known tradeoff between $R_{\mathrm{ON}}$ and $\mathrm{V}_{\mathrm{BK}}$. Because all the devices are not passivated, the $V_{B K}$ of the devices are not increased significantly.

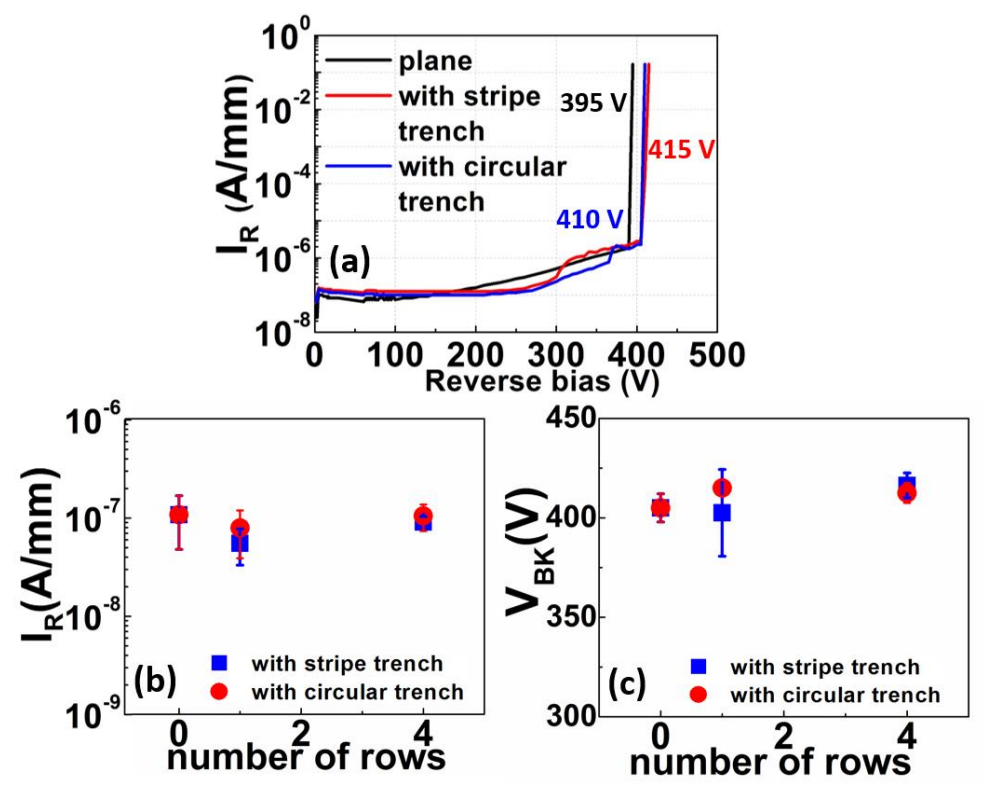

Figure 4. (a) the reverse-bias log scale (absolute values) two-pole characteristics for the SBDs with three different anode geometries (with four rows of circular anode trenches and $L_{A C}=10 \mu \mathrm{m}$ ); $(\mathbf{b})$ the $I_{R}$ (at reverse voltage up to $200 \mathrm{~V}$ ) for the SBDs with three different anode geometries $\left(\mathrm{L}_{\mathrm{AC}}=10 \mu \mathrm{m}\right)$ vs. rows of anode trenches; $(c)$ the $\mathrm{V}_{\mathrm{BK}}$ for the SBDs with three types of anode geometries $\left(\mathrm{L}_{\mathrm{AC}}=10 \mu \mathrm{m}\right) \mathrm{vs}$. rows of anode trenches.
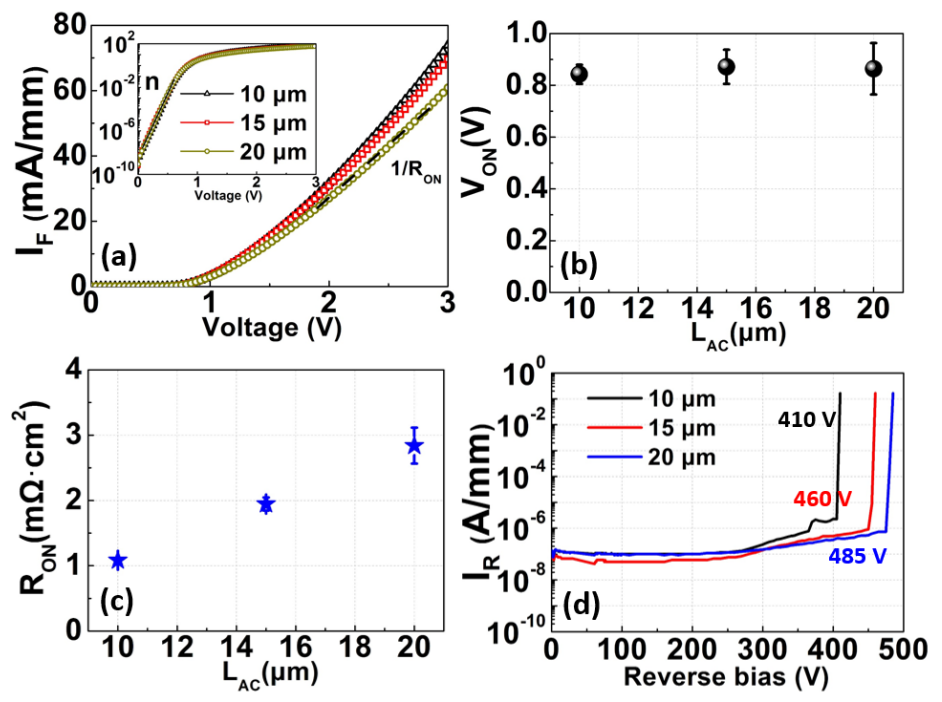

Figure 5. (a) the forward characteristics of the SBDs (with four rows of circular anode trenches) with different $\mathrm{L}_{\mathrm{AC}}$; (b) the $\mathrm{V}_{\mathrm{ON}}$ of SBDs (with four rows of circular anode trenches) with different $\mathrm{L}_{\mathrm{AC}}$; (c) the $\mathrm{R}_{\mathrm{ON}}$ of the SBDs (with four rows of circular anode trenches) with different $\mathrm{L}_{\mathrm{AC}}$; (d) the reverse-bias $\log$ scale (absolute values) two-pole characteristics for the SBDs (with four rows of circular anode trenches) with different $\mathrm{L}_{\mathrm{AC}}$. 


\section{Conclusions}

In conclusion, anode $\mathrm{AlGaN} / \mathrm{GaN}$ SBDs with three different anode geometries (the conventional plane, stripe, and circular one) have been fabricated. The SBDs with anode trenches possess lower $\mathrm{R}_{\mathrm{ON}}$ compared with conventional plane one. In addition, the SBDs with circular anode trenches enjoy lower $\mathrm{R}_{\mathrm{ON}}$ than that with stripe anode trenches at the same number of rows. Furthermore, the perimeter increases with the increase in the number of anode trenches because the proportion of the Schottky metal directly in contact with the 2DEG at the sidewall of the AlGaN/GaN interface increases, leading to a reduced $\mathrm{R}_{\mathrm{ON}}$. In addition, the SBDs with anode trenches exhibit reduced $\mathrm{R}_{\mathrm{ON}}$ without sacrificing the reverse characteristics compared with the conventional plane. Furthermore, the fabricated devices exhibit a low $\mathrm{I}_{\mathrm{R}}(<1 \mu \mathrm{A} / \mathrm{mm})$ and the $\mathrm{V}_{\mathrm{BK}}$ is not degraded by the anode trenches.

Author Contributions: Conceptualization, X.Y. and Y.Z.; methodology, Z.C. and Y.Z; validation, X.Y., Z.C. and Z.Y.; formal analysis, X.Y.; investigation, X.Y.; writing-original draft preparation, X.Y.; writing-review and editing, X.Y.; visualization, L.J.; supervision, L.Z. and Z.Y.; project administration, Y.Z.; funding acquisition, Y.Z. All authors have read and agreed to the published version of the manuscript.

Funding: This work was supported by the National Key Research and Development Program of China (Grant No. 2017YFB0402900), the Science Challenge Project (Grant No. TZ2018003), and the National Natural Science Foundation of China (Grant Nos. 61874176, 61674143, 61474102).

Conflicts of Interest: The authors declare no conflict of interest.

\section{References}

1. Zhang, Y.; Lu, X.; Zou, X. Device design assessment of gan merged p-i-n schottky diodes. Electronics 2019, 8, 1550. [CrossRef]

2. Gu, Y.; Chang, D.; Sun, H.; Zhao, J.; Yang, G.; Dai, Z.; Ding, Y. Theoretical study of inaln/gan high electron mobility transistor (hemt) with a polarization-graded algan back-barrier layer. Electronics 2019, 8, 885. [CrossRef]

3. Chen, W.; Wong, K.-Y.; Huang, W.; Chen, K.J. High-performance algan/gan lateral field-effect rectifiers compatible with high electron mobility transistors. Appl. Phys. Lett. 2008, 92, 253501. [CrossRef]

4. Ha, M.-W.; Lee, S.-C.; Choi, Y.-H.; Kim, S.-S.; Yun, C.-M.; Han, M.-K. New gan schottky barrier diode employing a trench on algan/gan heterostructure. Superlattices Microstruct. 2006, 40, 567-573. [CrossRef]

5. Chang, T.F.; Huang, C.F.; Yang, T.Y.; Chiu, C.W.; Huang, T.Y.; Lee, K.Y.; Zhao, F. Low turn-on voltage dual metal algan/gan schottky barrier diode. Solid State Electron. 2015, 105, 12-15. [CrossRef]

6. Lee, J.G.; Park, B.R.; Cho, C.H.; Seo, K.S.; Cha, H.Y. Low turn-on voltage algan/gan-on-si rectifier with gated ohmic anode. IEEE Electron. Device Lett. 2013, 34, 214-216. [CrossRef]

7. Bahat-Treidel, E.; Hilt, O.; Zhytnytska, R.; Wentzel, A.; Meliani, C.; Wurfl, J.; Trankle, G. Fast-switching gan-based lateral power schottky barrier diodes with low onset voltage and strong reverse blocking. IEEE Electron. Device Lett. 2012, 33, 357-359. [CrossRef]

8. Treidel, E.B.; Hilt, O.; Wentzel, A.; Würfl, J.; Tränkle, G. Fast gan based schottky diodes on si (111) substrate with low onset voltage and strong reverse blocking. Phys. Status Solidi 2013, 10, 849-852. [CrossRef]

9. Zhu, M.D.; Song, B.; Qi, M.; Hu, Z.Y.; Nomoto, K.; Yan, X.D.; Cao, Y.; Johnson, W.; Kohn, E.; Jena, D.; et al. 1.9-kv algan/gan lateral schottky barrier diodes on silicon. IEEE Electron. Device Lett. 2015, 36, 375-377. [CrossRef]

10. Tang, C.; Xie, G.; Zhang, L.; Guo, Q.; Wang, T.; Sheng, K. Electric field modulation technique for high-voltage algan/gan schottky barrier diodes. Chin. Phys. B 2013, 22, 106107. [CrossRef]

11. Matioli, E.; Lu, B.; Palacios, T. Ultralow leakage current algan/gan schottky diodes with 3-d anode structure. IEEE Trans. Electron. Devices 2013, 60, 3365-3370. [CrossRef]

12. Lenci, S.; De Jaeger, B.; Carbonell, L.; Hu, J.; Mannaert, G.; Wellekens, D.; You, S.Z.; Bakeroot, B.; Decoutere, S. $\mathrm{Au}$-free algan/gan power diode on 8-in si substrate with gated edge termination. IEEE Electron. Device Lett. 2013, 34, 1035-1037. [CrossRef]

13. Xu, Z.; Wang, J.Y.; Liu, Y.; Cai, J.B.; Liu, J.Q.; Wang, M.J.; Yu, M.; Xie, B.; Wu, W.G.; Ma, X.H.; et al. Fabrication of normally off algan/gan mosfet using a self-terminating gate recess etching technique. IEEE Electron. Device Lett. 2013, 34, 855-857. [CrossRef] 


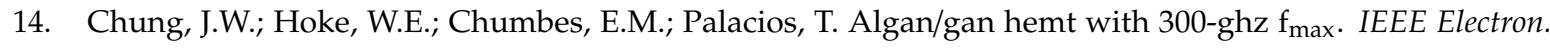
Device Lett. 2010, 31, 195-197. [CrossRef]

15. Kim, K.W.; Jung, S.D.; Kim, D.S.; Kang, H.S.; Im, K.S.; Oh, J.J.; Ha, J.B.; Shin, J.K.; Lee, J.H. Effects of tmah treatment on device performance of normally off al2o3/gan mosfet. IEEE Electron. Device Lett. 2011, 32, 1376-1378. [CrossRef]

16. Chan, C.-Y.; Lee, T.-C.; Hsu, S.S.H.; Chen, L.; Lin, Y.-S. Impacts of gate recess and passivation on algan/gan high electron mobility transistors. Jpn. J. Appl. Phys. 2007, 46, 478-484. [CrossRef]

17. Hsueh, K.-P.; Chang, Y.-S.; Li, B.-H.; Wang, H.-C.; Chiu, H.-C.; Hu, C.-W.; Xuan, R. Effect of the algan/gan schottky barrier diodes combined with a dual anode metal and a p-gan layer on reverse breakdown and turn-on voltage. Mater. Sci. Semicond. Process. 2019, 90,107-111. [CrossRef]

18. Shul, R.J.; Zhang, L.; Baca, A.G.; Willison, C.G.; Han, J.; Pearton, S.J.; Ren, F. Inductively coupled plasma-induced etch damage of gan p-n junctions. J. Vac. Sci. Technol. A 2000, 18, 1139-1143. [CrossRef]

19. Pearton, S.J. Characterization of damage in electron cyclotron resonance plasma etched compound semiconductors. Appl. Surf. Sci. 1997, 117-118, 597-604. [CrossRef]

20. Lian, Y.W.; Lin, Y.S.; Yang, J.M.; Cheng, C.H.; Hsu, S.S.H. Algan/gan schottky barrier diodes on silicon substrates with selective si diffusion for low onset voltage and high reverse blocking. IEEE Electron. Device Lett. 2013, 34, 981-983. [CrossRef]

21. Zhong, J.; Yao, Y.; Zheng, Y.; Yang, F.; Ni, Y.-Q.; He, Z.-Y.; Shen, Z.; Zhou, G.-L.; Zhou, D.-Q.; Wu, Z.-S.I.; et al. nfluence of dry-etching damage on the electrical properties of an algan/gan schottky barrier diode with recessed anode. Chin. Phys. B 2015, 24, 097303. [CrossRef]

22. Luo, J.; Zhao, S.-L.; Mi, M.-H.; Hou, B.; Yang, X.-L.; Zhang, J.-C.; Ma, X.-H.; Hao, Y. Trap states induced by reactive ion etching in algan/gan high-electron-mobility transistors. Chin. Phys. B 2015, 24, 117305. [CrossRef]

23. Yao, Y.; Zhong, J.; Zheng, Y.; Yang, F.; Ni, Y.; He, Z.; Shen, Z.; Zhou, G.; Wang, S.; Zhang, J. Current transport mechanism of algan/gan schottky barrier diode with fully recessed schottky anode. Jpn. J. Appl. Phys. 2015, 54, 011001. [CrossRef]

24. Tsou, C.W.; Wei, K.P.; Lian, Y.W.; Hsu, S.S.H. 2.07-kv algan/gan schottky barrier diodes on silicon with high baliga's figure-of-merit. IEEE Electron. Device Lett. 2015, 37, 70-73. [CrossRef]

25. Zhou, Q.; Jin, Y.; Shi, Y.Y.; Mou, J.Y.; Bao, X.; Chen, B.W.; Zhang, B. High reverse blocking and low onset voltage algan/gan-on-si lateral power diode with mis-gated hybrid anode. IEEE Electron. Device Lett. 2015, 36, 660-662. [CrossRef] 